\title{
PRODUCCIÓN Y TRANSFORMACIÓN DE LA VIVIENDA PORTUARIA MARPLATENSE EN LA PRIMERA MITAD DEL SIGLO XX
}

\section{MARIANA FERnÁndez OLIVERA}

Arquitecta, Facultad de Arquitectura, Urbanismo y Diseño de la Universidad Nacional de Mar del Plata, 2001. Becaria interna doctoral de CONICET, desde el 2003 con sede en el Centro de Estudios Históricos, Arquitectónicos y Urbanos, FAUD - UNMdP. Docente de la Cátedra Historia de la Arquitectura II, B, FAUD - UNMdP. Maestranda de la Maestría en Intervención en el Patrimonio Arquitectónico y Urbano, FAUD UNMdP. Doctoranda del Doctorado en Arquitectura, FAUD - UM. 


\title{
CUADERNOU::aAd
}

PRODUCCIÓN Y TRANSFORMACIÓN DE LA VIVIENDA PORTUARIA MARPLATENSE EN LA PRIMERA MITAD

\section{Resumen}

El siguiente trabajo se inscribe en la primera mitad del siglo XX en el marco del proceso de ampliación de la planta urbana de un sector de la ciudad de Mar del Plata que se forma en torno de la construcción del Puerto de Ultramar, alejado del centro fundacional y de importante recepción de migrantes. Estas especiales circunstancias, sumadas a la necesidad de alojamiento de las clases populares, permitieron el desarrollo de viviendas construidas en madera y chapa cuyas particularidades serán estudiadas a lo largo de este artículo. A través de un pormenorizado rastreo archivístico y mediante una investigación tipológica que permitió la clasificación y estudio en distintos niveles de análisis, se intenta aportar al conocimiento los aspectos que llevaron a la adopción de esta tipología y al proceso de transformación que sufrió como producto de nuevas representaciones.

\begin{abstract}
The following investigation is placed in the first half of the XX century in the setting of the amplification process of the urban plant of a sector of the Mar del Plata city which grew around the construction of the Ultramarine Port, faraway from the foundational center that had an important migratory reception. These special circumstances, plus the necessity for the lodging of the popular classes, allowed the development of housings constructed in wood and sheet metal which particularities we will be studied along this article. Through a careful research and by means of a typological investigation which allowed the classification and study in different levels of analysis, we will try to contribute to the knowledge of the aspects that introduced us to the adoption of this typology and the process of transformation that suffered as a result of new representations.
\end{abstract}




\section{Mariana Fernández Olivera}

PRODUCCIÓN Y TRANSFORMACIÓN DE LA VIVIENDA PORTUARIA MARPLATENSE EN LA PRIMERA MITAD DEL SXX

\section{INTRODUCCIÓN}

El barrio Puerto de Mar del Plata surge en el marco del proceso de extensión de las ciudades producido entre fines del siglo XIX y principios del siglo XX. Este "pueblo de pes cadores" ha sido, y sigue siendo, una sección del ejido con rasgos diferenciales respecto del núcleo urbano marplatense. La propia actividad pesquera y la fuerte presencia de inmigrantes definieron ciertas peculiaridades del sitio y de la arquitectura y sus materiales de construcción a través de la producción de viviendas de madera y chapa que dominaron el paisaje urbano hasta la década del cincuenta. Diversos factores condujeron a una percepción negativa, llevando a su paulatina transformación y pérdida. En este contexto, el siguiente trabajo tiene como propósito aportar al conocimiento de las prácticas de producción y transformación de la vivienda portuaria marplatense en la primera mitad del siglo XX, a partir de aspectos materiales y simbólicos.

Las investigaciones referentes al campo de conocimiento del hábitat popular distinguieron la existencia de casillas como una de las respuestas al problema de la vivienda en el período de formación de las ciudades modernas argentinas (Armus D. y Hardoy J.E., 1990; Liernur J.F., 1984 y 1993; Ramos J., 1998). En el orden local, existieron de dos tipos; aquellas relacionadas con la actividad balnearia y compuestas por una amplia gama de construcciones ribereñas como hoteles, comercios, ramblas, vestuarios, etc.; y aquellas habitadas por los pobladores permanentes y asociadas con un hábitat más precario debido a su carácter provisorio (Cova R., 1981 y Cacopardo F., 2004). A pesar de los variados ejemplos de asentamientos desarrollados con estas construcciones, ${ }^{1}$ no se ha abordado un estudio específico referente al área portuaria marplatense, cuyo caso resulta destacable en el marco del proceso de industrialización y urbanización argentino.

Se espera entonces contribuir al conocimiento general de la vivienda popular. Para ello, se plantea que los cambios en los aspectos materiales - referidos a materiales constructivos y tecnologías - y en los aspectos simbólicos — referidos a imágenes representativas, son el punto de partida para entender la dinámica de producción y transformación de la vivienda portuaria marplatense. El enfoque del trabajo será desde las prácticas no profesionales de construcción del espacio doméstico con el fin de aportar al conocimiento de
1- Las investigaciones en este campo escogen como caso paradigmático al barrio La Boca de Buenos Aires. Me interesa destacar investigaciones centradas en otra experiencia singular como fue la de ing. White de Bahía Blanca. Cf. Andreoli C., 2003. 


\section{CUADERNOU::aAn}

2- Sigo la definición de Luis Alberto Romero que entiende identidades como

cristalizaciones provisionales que aparecen en el momento en que, de un modo más o menos preciso, puede hablarse de un "nosotros", sea cual fuera esa identificación.

3- Método que retoma conceptos de la escuela italiana $y$ considera al "tipo" como un objeto abstracto, construido mediante el análisis, que reproduce las propiedades esenciales de una categoría de objetos reales y permite informar con economía y a la "tipología" como la lógica de las variaciones de los tipos.

4- Ver plano de ocupación de 1924 (intendencia de T. Bronzini) y plano catastral de 1936 (intendencia de $\mathrm{J}$. Camusso)

5- Esto fue parte de un proceso producido a escala nacional. Cf. Gorelik A., 1994; Gutiérrez R. y Nicolini A. 2000 y Rigotti A.M., 2000. los procesos de apropiación, resistencia y traducción en que los individuos de este sector construyeron sus identidades ${ }^{2}$ (Romero L.A., 1995). La comprensión de los procesos se abordó mediante el método de análisis tipológico3 (Panerai P., et. ál., 1983) realizado en función de una muestra representativa y en base a una importante combinación de distintas fuentes.

El desarrollo del texto está organizado en cuatro apartados. En el primero, se introduce a un panorama general sobre la ciudad, el barrio y la vivienda a principios del siglo XX, estableciendo relaciones entre el sector portuario, la villa balnearia marplatense y la imagen negativa de las construcciones de madera y chapa. En el segundo, se investiga el proceso de producción de las casillas en base a la muestra seleccionada. En el tercero, se analizan los factores que llevaron a la dinámica de cambio de la tipología y su relación con aspectos materiales y simbólicos. En el último, se formulan las conclusiones preliminares del presente trabajo.

\section{EL BARRIO DE LOS PESCADORES: CONSTRUCCIONES EFIMERAS VS. PROGRESO}

La ciudad de Mar del Plata no fue ajena al brusco crecimiento demográfico producido a escala nacional en la primera mitad del siglo XX, tanto por la llegada de población extranjera como por las migraciones internas. Como resultado, se originó una expansión de la planta urbana con el surgimiento de zonas periféricas de lo que resultó un área central densa y renovada y una serie de barrios distribuidos en los bordes de la ciudad cuya mayor restricción fue la accesibilidad. ${ }^{4}$ Si bien la extensión urbana fue pensada como una forma de solución para el asentamiento de las clases populares con promesas de acceso a "la casa propia", los mecanismos utilizados por parte de las clases dirigentes demostraron que en realidad lo que se buscaba era eliminar la pobreza de las zonas centrales. ${ }^{5}$ Esta búsqueda estuvo ligada al proyecto de construcción de la villa balnearia como centro de veraneo de las clases altas porteñas. Por otro lado, también significó un negocio para los sectores privados ya que aseguró la subdivisión y comercialización de tierras de su pertenencia.

Formando parte de ese proceso y como consecuencia del inicio de la obra para la construcción del Puerto de Ultramar en 1911, comenzó a gestarse el barrio Puerto en terrenos 


\section{Mariana Fernández Olivera}

\section{PRODUCCIÓN Y TRANSFORMACIÓN DE LA VIVIENDA PORTUARIA MARPLATENSE EN LA PRIMERA MITAD DEL SXX}

del Pueblo de Peralta Ramos, urbanización realizada en 1891 situada en la desembocadura del arroyo del Barco y comprendida por las actuales calles Juan B. Justo, Mario Bravo, Tetamanti y el mar. Sus características fueron marcadamente diferenciales a las de la "villa turística". Mientras el centro se fue definiendo con un carácter urbano-veraniego y el paisaje se enriqueció con edificaciones de residencias balnearias en diferentes estilos de moda, el sector portuario representó "la otra cara de Mar del Plata", conformando un pueblo apartado que recién fue incorporado al ejido de la ciudad en 1948. En la medida en que el Puerto de Ultramar comenzó a funcionar, fue polo de atracción al cual irían convergiendo los distintos grupos de pescadores, cuya procedencia era mayoritariamente italiana, ${ }^{6}$ que hacia 1890 residían en casillas sobre la playa Bristol y que en 1905 fueron obligados a trasladarse al barrio denominado La Pescadilla ${ }^{7}$. (Imagen 1)

En los inicios, una ocupación de carácter espontáneo se fue constituyendo en torno de dos actividades específicas: la construcción portuaria y la extracción de piedras de la cantera. Exceptuando dos edificios de la Empresa Constructora del Puerto, el resto eran casillas de chapa y madera. Para 1922 un periodista de la revista Caras y Caretas describía el aspecto que tenía la zona por ese entonces: “... ¿Quésignifica ese montón de latas que brillan en un bajo y que deslumbran a los que juegan en el Golf? (...) Es un barrio de Mar del Plata. Son obreros que trabajan en la piedra de las canteras o en las aguas del mar (...) Estapoblación se ha improvisado junto al puerto. Es un caserío del Far-West...". Entre fines de la década del'30 y principios del ' 40 se produjo un auge en materia económica del sector pesquero provocando la instalación de saladeros y fábricas de conserva y la modificación definitiva de la zona. El fraccionamiento gradual de las tierras ${ }^{9}$ ocasionó un ensanche del ejido original con la consecuente ampliación de la ocupación. A ello se le sumó la construcción de una serie de edificios de relevancia como la Usina

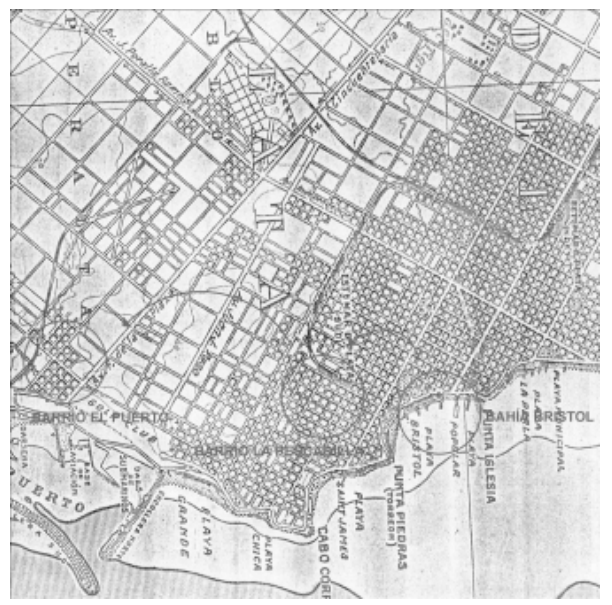

6- En especial italianos del sur - sicilianos y de las islas del golfo de Nápolesaunque también existió un aunque tambien existio un
núcleo de marchegianos. En Di Iorio J.A., 26/6/1947, "Desde la barca mía. Los pescadores de nuestro mar", Semanario El Puerto, Mar del Plata.

\section{7- Para ampliar al respecto ver un trabajo anterior: Fernández Olivera M., 2004, "Historia urbana y vivienda popular. El barrio Puerto de popular. El barrio Puerto de Mar del Plata entre 1910 y
$1950 ”$, Revista Registros, 2, Mar del Plata, CEHAU. FAUD-UNMdP.}

8- Soiza Reilly J.J., 25/2/1922, "Un pueblo del Far-West en Mar del Plata”, Caras y Caretas, Buenos Aires.

9- Ver Folletos Inmobiliarios de varios martilleros décadas del '20, '30 y '40, Archivo y Museo Histórico Municipal. Ver planos de mensura y división de tierras, expedientes municipales de Obras Públicas 91-M-1925 y 86B-1926.

Imagen 1- Plano catastral de 1936 (intendencia de J. Camusso), se indica el traslado que sufrieron los pescadores y se observa el carácter periférico del barrio Puerto. Fuente: Archivo y Museo Histórico Municipal de Mar del Plata. 


\section{CUADERNO}

PRODUCCIÓN Y TRANSFORMACIÓN DE LA VIVIENDA PORTUARIA MARPLATENSE EN LA PRIMERA MITAD DEL SXX

\begin{abstract}
10- Fue el auge de la arquitectura industrial que implicó la construcción de puertos y el tendido de ferrocarriles $y$, en ese contexto, surgieron empresas que importaban o construían viviendas prefabricadas, modelos que también fueron repetidos por los sectores populares. En el orden local la empresa Tiribelli Hnos. ofrecía catálogos con diferentes modelos prefabricados que estaban a la venta.
\end{abstract}

11- El Reglamento para la Construcción en Playa Bristol de
1899 prohibía la construcción de casillas para habitación en el espacio comprendido entre el Boulevard Marítimo y la orilla del mar. Una ordenanza de mismo año las prohibía con frente a la calle y a menos de 5 metros de la línea municipal en el radio comprendido por las calles 25 de Mayo, Belgrano, Independencia y Boulevard Marítimo. Completarán esta serie los Reglamentos de Construcciones de 1907, $1933 y$ 1937 con el paulatino aumento del área de prohibición. Cf. Bruno P., 1997

Imagen 2- A la izquierda, plano del estado de la edificación para 1924 (intendencia de T. Bronzini). A la derecha, plano en base a la aerofoto de 1935 (intendencia de J. Camusso), se señalan los edificios singulares construidos hasta ese momento.

Fuente: Archivo y Museo Histórico Municipal de Mar del Plata.
(1928), la Iglesia y Colegio Sagrada Familia (1928), el Colegio Inmaculada Concepción (1935), la Delegación Municipal (1936), la Gruta de la Virgen de Lourdes (1937) y dos Conjuntos de Viviendas Obreras (1942 y 1944). (Imagen 2)

Acompañando al proceso de expansión, el problema del hábitat popular se constituyó como tema central. Para 1930 una buena cantidad de las viviendas de la periferia marplatense estaban construidas en madera y chapa (Cova R., 1981). Eran viviendas móviles, autoconstruidas o prefabricadas ${ }^{10}$, que seguían un modelo de ordenamiento espacial repetido subordinado a la dimensión del lote disponible. Ello dio lugar a una conformación tipológica compacta, de reducidas dimensiones, compuestas por una o dos habitaciones, galería exterior y retrete al fondo. Representaron una imagen negativa tanto desde la seguridad y la higiene como desde aspectos estéticos y por ello las reglamentaciones tendieron a limitar su construcción y a alejarlas del centro fundacional de la ciudad en la medida que avanzaba el progreso (Cacopardo F., 1997 y Bruno P. 1999). Desde principios de siglo, aludien-

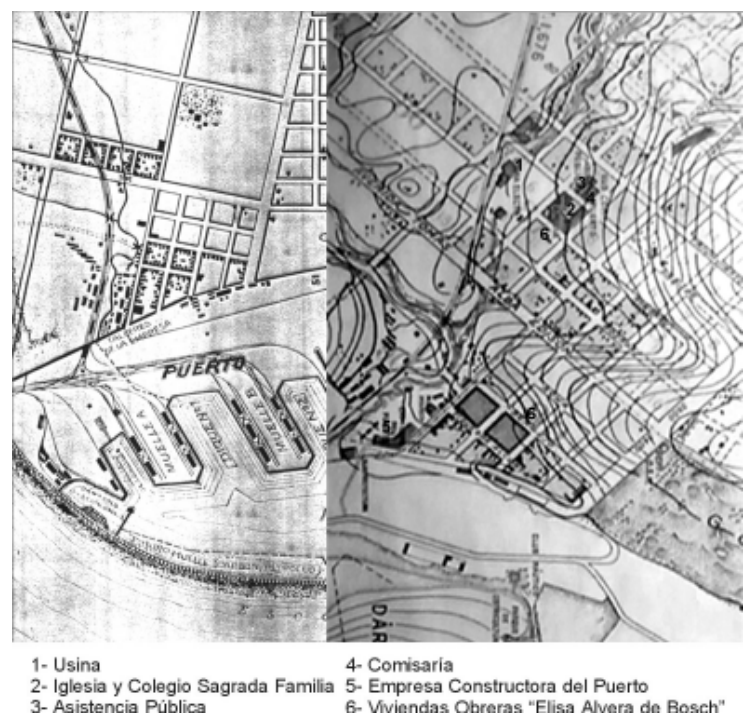
do a cuestiones higienistas, se intentó eliminar a un tipo de construcción que no coincidía con el aspecto que se buscaba para a la villa turística aristocrática. ${ }^{11}$

El censo de población realizado en 1937 por la municipalidad establecía que el problema de la vivienda obrera debía resolverse en primer término en el barrio Puerto ya que la colonia de pescadores vivía hacinada en malísimas viviendas de madera y chapa, y en pésimas condiciones de salubridad. Asimismo, agregaba que "...en lascasillas de madera, zincy chapay demás construcciones de lazona portuaria viven 2536 personas entre las que figuran 186 


\section{Mariana Fernández Olivera}

\section{PRODUCCIÓN Y TRANSFORMACIÓN DE LA VIVIENDA PORTUARIA MARPLATENSE EN LA PRIMERA MITAD DEL SXX}

matrimonios de pescadores (...), sólo una terceraparte (...) es propietaria del terreno y de la vivienda que ocupan...".12 Por otro lado, no es un hecho menor que se concentraran en esta área inmigrantes italianos dedicados a la pesca, ya que desde el punto de vista social contribuyó a la formación de un grupo con una fuerte identidad barrial. En ese sentido, el papel que ocupaba en el universo simbólico de estos inmigrantes la religiosidad popular fue un campo propicio para el desarrollo de instituciones religiosas (Castro M.O., 2001).

Desde los orígenes del Puerto fue importantísima la labor de la Comisión Auxiliar de la Damas Vicentinas, organización de beneficencia integrada por mujeres de la elite que, junto a los sacerdotes de la Obra Don Orione, tenían por objeto la reforma de los modos de habitar de los sectores populares. ${ }^{13}$ En este marco, se insertó un conjunto de obras de la Iglesia Católica, que en la escala doméstica adquirieron manifestación con la construcción de los dos barrios obreros Elisa Alvear de Bosch, construidos en 1942 y en 1944, cuyos diseños incorporaban una serie de características basadas en la higiene, el progreso edilicio y la catolicidad, con el fin de solucionar el problema habitacional y como un peldaño en el progreso social del barrio.

La acción institucional adquirió su máxima expresión a través del Semanario El Puerto, aparecido en 1941, que mediante sus publicaciones promovió un discurso en contra de estas casillas que simbolizaban una imagen del retroceso: "...el villorrio proletariado poblado de covachas y de pocilgas inhospitalarias, como este sórdido caserio de maderas y chapas viejas de lazona portuaria, que también forman parte, y muy importante, del gran balneario que aspira a ser uno de los primeros centros de turismo del mundo...", "...losmateriales de que estân hechas sus viviendas y la promiscuidad de las familias instaladas en ellas conspiran contra la salud pública...", "....se trata de un verdadero derrotismo contra el progreso y la cultura que propietarios regresivos y retardarios realizan, por ignorancia, contra sus propios intereses morales y materiales,..., oponiéndose al progreso edilicio, resistiéndose a construir cercos y veredas o levantando casillas de viejay apolillada madera ode chapas deterioradas...."16

En este contexto, la realidad barrial se presentaba sumamente compleja. La situación habitacional de los trabajadores de la pesca era muy precaria. El Estado, no se hacía cargo del problema y la falta de regulación promovía la libre especulación sobre las tierras. Asimismo, el accionar de la elite junto al de la Iglesia Católica avanzaba sobre el
12- Boletín Municipal, $2^{\circ}$ trimestre 1937, p: 149.

13- Se enmarcó en el proyecto Gran Colecta Nacional Pro Paz Social donde la vivienda fue concebida como instrumento reformador. Cf. Ballent A., 1990.

14- 25/6/42, “Transformación y mejoramiento urbano de la zona portuaria”, Semanario El Puerto.

15- 31/1/42, “Artículo de La Prensa sobre el barrio de los Pescadores", Semanario El Puerto.

16- 9/5/42, "Desorden en la edificación”, Semanario El Puerto. 


\section{CUADERNOU⿴囗十⺝}

PRODUCCIÓN Y TRANSFORMACIÓN DE LA VIVIENDA PORTUARIA MARPLATENSE EN LA PRIMERA MITAD

DEL SXX

17- La denominación de cada sector se realiza con el fin de facilitar la comprensión de la lectura del artículo. ámbito privado mediante obras de beneficencia y publicaciones en el diario barrial. ¿Cómo era la constitución material de este sector?, ¿cómo se fue modelando la tipología entre las necesidades de las clases populares y los intereses de los sectores dirigentes? Para responder a estos interrogantes se realiza una reconstrucción material de un fragmento urbano del barrio Puerto entre los años 1920 y 1950, período de desarrollo y consolidación del área de estudio.

\section{LA VIVIENDA DE LOS PESCADORES: EL DESARROLLO DE UNA TIPOLOGÍA SINGULAR}

Al observar la evolución urbana del barrio Puerto en el período de estudio se distinguen tres sectores urbanos (Imagen 3). Un sector primigenio, ${ }^{17}$ donde se ubican las primeras edificaciones relacionadas con las actividades productivas y comerciales de la zona. Un sector viejo, formado en torno a la Iglesia y el Colegio Sagrada Familia, de carácter residencial. Y un sector nuevo, ubicado al otro lado de la vía del ferrocarril y lindante con la usina eléctrica, también de carácter residencial. Se trabajó con estos dos últimos, de los que se obtuvieron 111 lotes ocupados con viviendas de madera y chapa. Los datos fueron extraídos de las planchetas catastrales, el plano realizado en base a la aerofoto de $1935 \mathrm{y}$ los expedientes municipales de obras públicas y privadas. Su estudio ha sido abordado a través de tres variables de análisis: la tecnología, la organización espacial y la relación con el entorno, aspectos que han permitido su comprensión y diferenciación. (Imagen 3)

Las primeras edificaciones en lo que hemos denominado el "sector viejo" se registran a mediados de la década del '20. Sin duda, la construcción de la Iglesia y Colegio Sagrada Familia en 1928 fue un hecho determinante para su desarrollo. Lo que se conoció como "sector nuevo" comenzó a formarse a mediados de la década del ' 30 y, sin embargo, las viviendas ubicadas allí respondieron a la misma tipología. Las fuentes muestran que de los 111 lotes ocupados con casillas, 98 eran viviendas únicas, 9 incluían 2 viviendas por lote y 4 eran viviendas colectivas.

Estas casillas, en su organización espacial, presentaban grandes similitudes con la casa chorizo, definidas a partir una sucesión de habitaciones perfectamente moduladas en $4 \mathrm{x}$ 4 metros aproximadamente y articuladas a través de una galería cerrada. La planta estaba organizada en dos zonas bien diferenciadas: las habitaciones, que no tenían un uso espe- 


\section{Mariana Fernández Olivera}

\section{PRODUCCIÓN Y TRANSFORMACIÓN DE LA VIVIENDA PORTUARIA MARPLATENSE EN LA PRIMERA MITAD DEL SXX}

cífico, y la galería, área pública de recepción, comedor y cocina. Conformando una construcción independiente se encontraba el baño, espacio segregado del orden jerárquico de los ambientes y ubicado al fondo del terreno. Este tipo de organización permitía la construcción por etapas en concordancia con la movilidad social imperante en ese momento: ante el aumento de recursos o ante la llegada de nuevos familiares se podían agregar nuevas habitaciones. Por otro lado, la indiferenciación de sus espacios permitía la flexibilidad posibilitando su transformación en distintos usos.

Respecto del aspecto tecnológico, adquirió un papel rector en el diseño con el respeto por una modulación que estaba acorde con las dimensiones y economía de los materiales, y la posibilidad de ampliación mediante el crecimiento y acoplamiento de partes. La austeridad y racionalidad no sólo se reflejaban en la modulación en planta sino también en el sistema constructivo: un esqueleto de madera cuyo módulo estaba determinado por la medida de las chapas que revestían la vivienda. Un costo relativamente reducido de los materiales, acorde con las posibilidades de este sector social; la facilidad de un rápido armado, que permitía la autoconstrucción; y la movilidad, por su característica desmontable y su bajo peso relativo, fueron los principales factores que influyeron en la adopción de este sistema.

La casilla se montaba en seco colocándose sobre puntales de madera a unos 50 centímetros sobre la tierra a fin de permitir la ventilación, evitar el ataque de hongos por la humedad y protegerse de las inundaciones. Asimismo, la elevación facilitaba colocar los ejes y las ruedas, para ser tirada por caballos, en caso de querer ser trasladada. Se apoyaba sobre puntales de madera sobre los que se acomodaban las vigas maestras

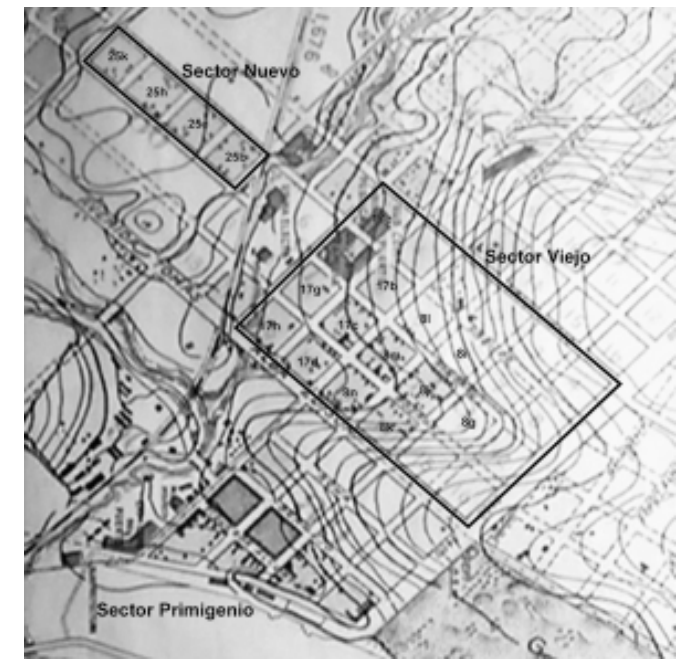

Imagen 3- Se señalan en el plano realizado en base a la aerofoto de 1935 (intendencia de J. Camusso) los sectores seleccionados como muestra. Las manzanas con nomenclatura catastral eran las ocupadas. 


\section{CUADERNOU⿴囗十⺝}

PRODUCCIÓN Y TRANSFORMACIÓN DE LA VIVIENDA PORTUARIA MARPLATENSE EN LA PRIMERA MITAD

que recibían a los paneles y los tirantes sobre los que se clavaba el piso compuesto por tablas machimbradas. La estructura de los paneles estaba compuesta por un tirante inferior, uno superior y pies derechos modulados que, cuando era necesario, dejaban espacio para puertas y ventanas con el dintel y la solera correspondiente. Finalmente, sobre cada parante se colocaba una cabriada que sostenía la tirantería sobre la que se clavaba la cubierta de chapa. La estructura de la galería estaba girada a $90^{\circ}$ respecto de las habitaciones. El techo se armaba a continuación del otro, con tirantes que apoyaban en vigas laterales y éstas en las columnas de la galería. El exterior se cubría con chapa de cinc acanalada ubicada en sentido vertical o madera machimbrada en sentido horizontal. El revestimiento interior también era de madera y los paneles se armaban con las mismas características que los exteriores pero con una estructura más liviana. Tanto puertas como ventanas poseían medidas estándares y se cerraban con postigones.

En cuanto a su adaptabilidad a las condiciones del entorno, se tendrán en cuenta aspectos del entorno natural como condicionantes económicos. La especulación imperante, en busca de la máxima rentabilidad, trajo aparejada una división de la manzana en lotes angostos de 8,66 metros de frente. Por ello, esta tipología se convierte en la más viable, por un lado, debido a que su organización se adapta a la forma del terreno siguiendo el sentido longitudinal y, por orto lado, permitiendo al propietario de las tierras subdividir al máximo, aumentando la renta inmobiliaria en concordancia con el rápido crecimiento poblacional.

La casilla se ubicaba hacia uno de los lados del lote, dejando un espacio libre del eje medianero para evitar la propagación de incendios. El acceso se realizaba a través del patio lateral que estaba en relación directa con la zona pública. Al frente se dejaba otro retiro marcando un límite con la calle. La puerta del acceso principal estaba alineada con el patio lateral y el circuito de acceso era lineal y paralelo a la organización de la vivienda. El perímetro libre fue configurando un tejido abierto sumado a que las medianeras no estaban materializadas. Una serie de construcciones sueltas en la manzana, calles de tierra no muy definidas y lugares pantanosos daban el aspecto de una zona rural. El sistema constructivo, trasladable y sobreelevado, se adecuaba perfectamente a las condiciones naturales del sitio, pantanoso e inundable. Asimismo, la forma de implantación en el lote y la falta de vinculación con la medianera daba cuenta del carácter 


\section{Mariana Fernández Olivera}

PRODUCCIÓN Y TRANSFORMACIÓN DE LA VIVIENDA PORTUARIA MARPLATENSE EN LA PRIMERA MITAD DEL SXX

móvil de estas casillas que la mayoría de las veces se asentaban en terrenos alquilados o invadiendo tierras fiscales o privadas, estando sujetas a continuos desplazamientos impuestos por el municipio o por el propietario del terreno. ${ }^{18}$

De estas características comunes y en base al análisis tipológico realizado, se han elaborado seis tipos de casillas (Imagen 4). El tipo l, formado por una habitación con o sin galería exterior. El tipo 2, por una habitación y cocina, se presenta en dos variantes: a) con cocina al costado de la habitación, y b) con cocina sobresaliendo de la habitación. El tipo 3, por dos habitaciones y cocina, también se presenta en dos variantes: a) con cocina dando a una galería exterior, y b) con cocina al costado de las habitaciones. El tipo 4, por dos habitaciones, cocina y galería cerrada. El tipo 5, con tres o cuatro habitaciones, cocina y galería cerrada. Finalmente, la casilla colectiva comprendida por una sucesión de habitaciones con cocinas. (Imagen 4)

\section{ESTRATEGIAS DE ASCENSO SOCIAL: TRANSFORMACIONES MATERIALES Y RE- PRESENTACIONES SIMBÓLICAS}

Se indaga ahora en los procesos de transformación de estas viviendas, distinguiéndose dos momentos. En la primera mitad de la década del ' 30 se observan los primeros umbrales de cambio. Para esta época se construyen casillas tipo 4 y 5 , ya sea por ampliación de una casilla tipo 1, 2 o 3, o por construcción nueva. La característica de éstas fue que la cocina se diferenció de la galería cerrada que hacía de espacio de recepción. Observando la Imagen $5^{19}$ se destacan los siguientes cambios:

independencia de la cocina, agregándose un módulo a la organización típica de la casilla (parc. 8j-12, 8k-25, 8m-26, 8n-23, 17c-1l, 17g-17, 17g-22, 17h-20, 25e-14, 25e-20, 25h-10a, 25k-5 y 25k-21) o separándola de la zona de recibo (parc. 8j-1, 8m$4,8 \mathrm{~m}-5$ y $25 \mathrm{k}-13)$;

incorporación del baño a la organización de la vivienda, pegándose a la cocina (parc. 8m-5 y 25k-5) o integrándose a la circulación principal (parc. 8m-7, 8m-22, $8 \mathrm{n}-23,25 \mathrm{e}-14$ y $25 \mathrm{e}-20)$

diversificación de la galería, diferenciándose en comedor y vestíbulo (parc. 8j-1, $8 \mathrm{j}-12,8 \mathrm{~m}-4,8 \mathrm{~m}-5$ y $25 \mathrm{k}-13$ ). (Imagen 5 ) 


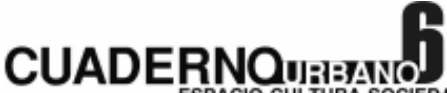

PRODUCCIÓN Y TRANSFORMACIÓN DE LA VIVIENDA PORTUARIA MARPLATENSE EN LA PRIMERA MITAD DEL SXX

Estas transformaciones que implicaron un crecimiento o una variación de las tipologías básicas con la incorporación de áreas de servicios y de áreas públicas se producen tanto en el sector nuevo como en el sector viejo. La cocina aparece como un espacio que deja de formar parte del área más pública para convertirse en un ambiente con una función específica. Este cambio, en algunos casos se origina mediante la ampliación de una habitación pegada a la vivienda pero segregada del orden jerárquico de los ambientes, y en otros casos, a través de la incorporación plena a la organización interna de la casilla. El baño pasa de ser un galpón con una letrina ubicado al fondo del terreno a un espacio diferenciado funcionalmente que, aunque sigue estando fuera de la circulación principal y se accede externamente, constituye un avance en la típica conformación de estas

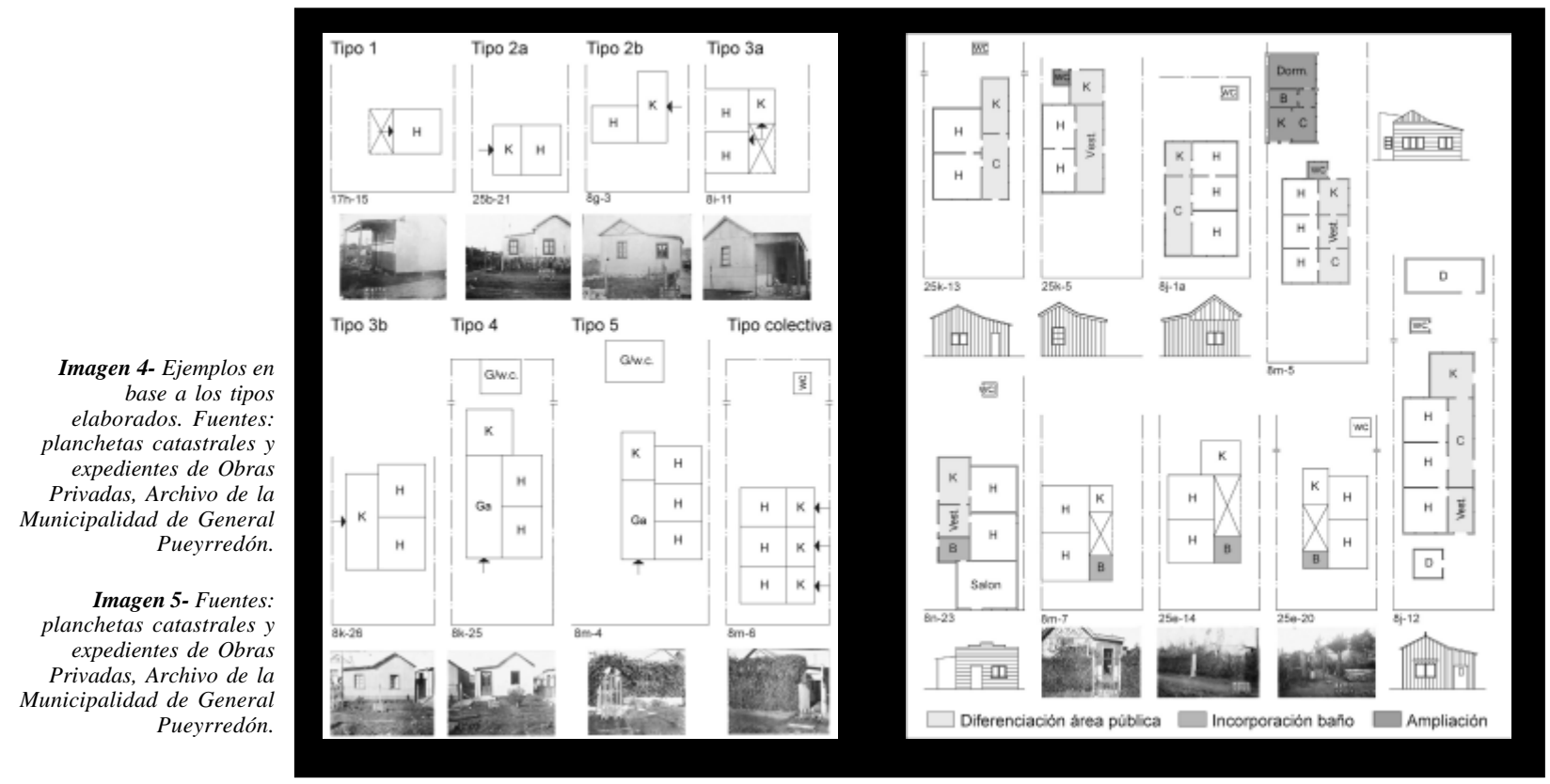




\section{Mariana Fernández Olivera}

PRODUCCIÓN Y TRANSFORMACIÓN DE LA VIVIENDA PORTUARIA MARPLATENSE EN LA PRIMERA MITAD DEL SXX

casillas. Por último, el comedor se presenta como un espacio jerarquizado e independiente de la cocina y se agrega un vestíbulo con función específica de recepción.

Por otro lado, en referencia a la Imagen $6,{ }^{20}$ se observan, ya avanzando hacia la década del 40, otro tipo de transformaciones en el sector viejo:

ampliación de material ${ }^{21}$ que sigue el mismo esquema organizacional y deja detrás la letrina (parc. 8j-13, 8j-22, 17c-14, 17h-19 y 17h-21);

construcción de vivienda de material detrás de la casilla (parc. 8i-11, 8j-29 y 8m-26);

reemplazo de la casilla por vivienda de material (parc. 8g-15, 8g-19, 8m-2 y 8m-3);

construcción de vivienda de material delante y traslado de la casilla al fondo del lote (parc. 8g-5g, 8m-7, 8m-18, 17c13 y $17 \mathrm{c}-18)$;

ampliación hacia el frente incorporándose a la casilla dormitorio, vestíbulo y porche (parc. 8j-19); transformación de la fachada (parc. $8 \mathrm{j}-27,8 \mathrm{~m}-22$ y $25 \mathrm{~h}-26$ ). (Imagen 6)

En estas modificaciones surgen los primeros cambios notorios con la incorporación de otro sistema constructivo. Las ampliaciones o la construcción de una nueva vivienda, el reemplazo de la casilla o su traslado al fondo del lote y la modificación de la fachada imitando otras tipologías, tal cual una escenografía, son aspectos demostrativos de otro orden de cambios. ¿Qué nos dicen estas transformaciones?, iha cambiado la forma de concebir la vivienda?, ¿a qué nuevas representaciones responden?, ¿podemos hablar del inicio de un proceso de modernización?

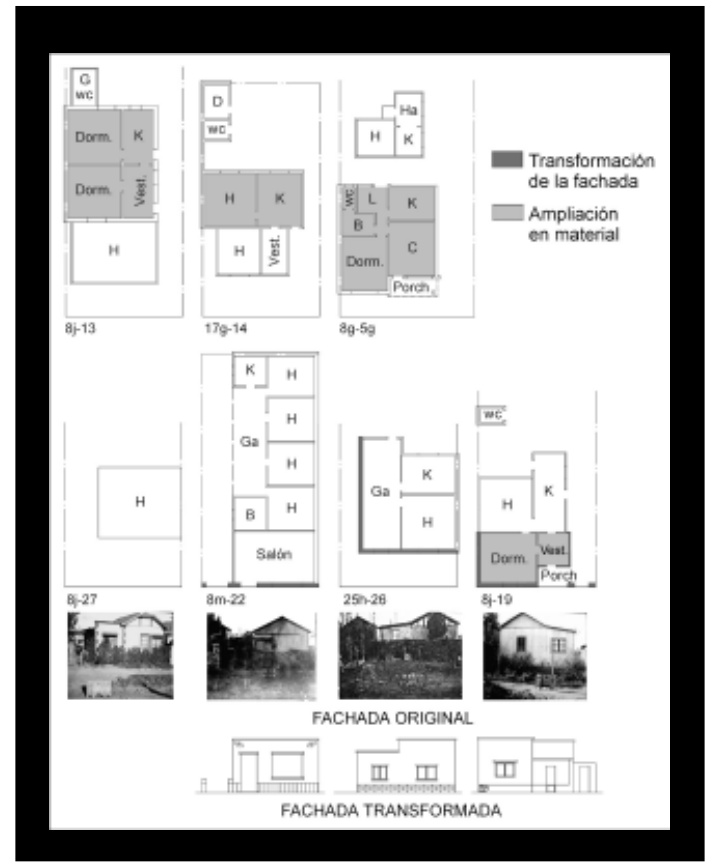

20- Op. cit. nota 19 .

21- Materiales sólidos, mampostería.
Imagen 6- Fuentes: planchetas catastrales $y$ expedientes de Obras Privadas, Archivo de la Municipalidad de General Pueyrredón. 


\section{CUADERNOU::aAn}

PRODUCCIÓN Y TRANSFORMACIÓN DE LA VIVIENDA PORTUARIA MARPLATENSE EN LA PRIMERA MITAD

22- En las manzanas $8 g$, $8 j$, $8 \mathrm{~m}, 17$ c y $17 \mathrm{~g}$.

23- Braulio Arenas, Crisanto y Rogelio Letamendía, Carmen Sánchez de Letamendía, Alicia Peralta Ramos de Hernández, Pascual Marcone, Castelo Altro, Bembenuto Cayetano, Soc. Galo Llorente y Francisco Coquet son algunos de los propietarios de las tierras.

Según planchetas catastrales y plano de subdivisión expediente municipal $71-B$ -

1920.
La modernización del espacio doméstico implicó la especialización de las funciones y la separación clara de espacios públicos y privados. En respuesta a los interrogantes planteados y a partir de las variaciones observadas, podemos hablar de una tendencia en ese sentido. Así, la división de la galería en espacios para cocinar, comer o recibir, o la incorporación del baño en el esquema distributivo de la vivienda son demostrativas del avance modernizador. Por otro lado, las transformaciones que modifican la relación público-privado, la lógica de la estructura parcelaria o la materialidad de la casilla manifiestan nuevas representaciones simbólicas.

Sin duda, los cambios están relacionados con una mayor estabilidad que se observa principalmente en lo que hemos denominado el sector viejo, y en particular en las manzanas centrales de mayor densidad de ocupación y cercanas a la Iglesia. ${ }^{22}$ Allí es donde se ubican las casillas colectivas como consecuencia del proceso especulativo y del alza del valor de la tierra. Asimismo, en este período, se producen cambios en la propiedad. Según las planchetas catastrales se observa que muchas de las casillas han sido terminadas antes que las tierras fueran vendidas por sus propietarios originales, dueños de manzanas enteras. ${ }^{23}$ Evidentemente esto se daba porque había una ocupación ilegal o porque la vivienda era alquilada. En cualquiera de los casos, en coincidencia con la adquisición de la propiedad, el nuevo propietario realizaba las ampliaciones, modificaciones o reemplazos correspondientes. Por lo tanto, esto está indicando un progreso en la escala social, que para estos grupos estaba dado por la tenencia propietaria.

Sin embargo, en muchos de los casos en los que existe este cambio propietario, o inclusive en lotes que estaban vacíos y son ocupados con una construcción, el sistema de madera y chapa sigue vigente. Los materiales analizados muestran la amplia difusión y apropiación por parte de los habitantes del Puerto de estas casillas, y por ello, una cierta resistencia al cambio reflejada en transformaciones aparentes. En ese sentido, se distingue una imitación de otros modelos de vivienda popular construidos en material, simulando una mejora social, ya que esos modelos estaban asociados con niveles sociales más altos y a condiciones económicas más estables. Así, en las representaciones que los sectores populares construyeron sobre el mundo moderno - que era asociado a lo urbano- lo simbólico jugó un papel fundamental, y por ello, la fuerte tensión entre lo que se mostraba y lo que estaba detrás. 


\section{Mariana Fernández Olivera}

\section{PRODUCCIÓN Y TRANSFORMACIÓN DE LA VIVIENDA PORTUARIA MARPLATENSE EN LA PRIMERA MITAD DEL SXX}

En ese proceso de resistencia al cambio de un modelo ampliamente difundido y apropiado por los pescadores, el mensaje promovido por las instituciones dominantes, a partir de aspectos morales e higiénicos, tuvo una notable influencia en la construcción de un imaginario simbólico negativo respecto de las casillas de madera y chapa. No es casual que, en base al censo realizado en 1937, el municipio prohibiera las construcciones en madera y chapa en la zona comprendida por las calles Rondeau, Centenario (hoy Juan B. Justo), la vía del ferrocarril y el mar, ${ }^{24}$ que coincidía con el sector primigenio y que para ese entonces era la zona más consolidada y de mayor desarrollo. Tampoco son casuales las publicaciones del Semanario portuario y el accionar de la Iglesia Católica durante la década del ${ }^{\circ} 40$.

En este marco, los sectores populares habitantes del Puerto construyeron una imagen de urbanidad donde coexistió la permanencia de un modelo y los inicios de una transformación. En este proceso dual, hubo traducciones como recepción del mensaje impartido, que se reflejaron en el espacio doméstico. En un ambiente precario, donde todavía había huertas, animales y letrinas, comenzaron a aparecer elementos representativos de un nuevo orden, conviviendo el mundo rural y el urbano. Unos u otros cambios no fueron ni tan claros ni tan radicales. Observando las transformaciones, de alguna manera cambió la forma de concebir la vivienda. Sin embargo, esas transformaciones concluyeron en una tipología intermedia que siguió los cánones generales de la casilla pero que tomó elementos particulares de otras tipologías provocando una especie de híbrido - mutante si se quiere- entre una y otra. La división entre las distintas formas del hábitat popular ranchos, casillas, casa chorizo, etcétera- minimiza una relación que fue mucho más difusa, con muchos matices, simplificando la lectura de un mundo material complejo, donde el proceso de construcción de la vivienda propia estuvo ligado al progreso del inmigrante y al diálogo entre éste y las representaciones sociales.

\section{CONCLUSIONES FINALES: ¿DE LA CASILLA A LA CASA DE MATERIAL?}

Se trabajó en un barrio periférico de Mar del Plata que formó parte de "otra ciudad" y que, siendo un sector portuario, alejado del centro fundacional y receptor de un importante caudal de inmigrantes, se definió con características muy propias. El trabajo se realizó en base a un pormenorizado análisis de fuentes archivísticas indagando en el mundo

24- Reglamento General de Construcciones de 1937, Capítulo XIV, Artículo 92. 


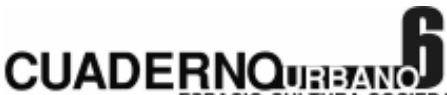

PRODUCCIÓN Y TRANSFORMACIÓN DE LA VIVIENDA PORTUARIA MARPLATENSE EN LA PRIMERA MITAD

DEL SXX

material popular con el fin de aportar a una tipología de vivienda que, a pesar de su reconocimiento en los últimos años, aún presenta muchos interrogantes. La producción del hábitat popular del barrio Puerto marplatense estuvo ligada con circunstancias sociales, económicas y culturales muy particulares y, en la medida en que esas circunstancias se fueron modificando, también lo hizo la vivienda.

La adopción de un sistema constructivo ampliamente difundido en zonas portuarias estuvo ligada con el bajo costo de su construcción, a que no requería mano de obra especializada, a la rapidez de su armado y a la ventaja de poder ser trasladado. Por otro lado, su organización en planta posibilitaba la ampliación por etapas y la flexibilidad de las habitaciones en concordancia con la inestabilidad de este sector, satisfaciendo las necesidades inmediatas de alojamiento. Todos estos aspectos tuvieron notable influencia en la apropiación de la tipología. Paralelamente a la difusión de este modelo, se contrapuso un discurso desde las instituciones dominantes. Temiendo que lo transitorio se volviera permanente, se promovió en el imaginario social la relación de estas casillas con aspectos antihigiénicos, cuando en realidad lo que molestaba, era la imagen de precariedad que se contraponía a la imagen de progreso que se buscaba para la ciudad y el barrio. Durante la década del` 40 , se promovieron cambios sustanciales en la concepción de la vivienda popular portuaria como consecuencia de este discurso.

Las transformaciones estuvieron influidas por múltiples matices. El anhelado progreso económico de los sectores populares, la difusión de nuevos modelos de vivienda popular y el categórico discurso institucional apoyado por el municipio, difundido por el semanario barrial y llevado a cabo por la Iglesia Católica a través de obras de objeto reformador, fueron aspectos propicios para el desarrollo del cambio. Sin embargo, el proceso de transformación no fue lineal, en la búsqueda de ascenso social de los sectores populares la vivienda se concibió como una estrategia donde se confundieron las aspiraciones personales y las nuevas representaciones del mundo urbano asociado con el progreso.

En la construcción de esa imagen de urbanidad, se distinguieron las resistencias al cambio, las imitaciones de otros modelos y sus traducciones. Los múltiples intereses de los distintos actores se vieron reflejados en el espacio doméstico, y por ello, las clasificaciones tipológicas no fueron ni tan claras ni tan estructuradas y, en la realidad, unas y otras 


\section{Mariana Fernández Olivera}

PRODUCCIÓN Y TRANSFORMACIÓN DE LA VIVIENDA PORTUARIA MARPLATENSE EN LA PRIMERA MITAD DEL SXX

se confundieron conformando artefactos híbridos y mutantes, expresivos de los cambios sociales producidos. En tal sentido, se complejiza la representación, en general homogénea, de la vivienda popular y, en particular, de este barrio marplatense, en un espacio donde confluyeron las ideas moralizantes e higienistas de las clases altas, las representaciones religiosas, la especulación inmobiliaria, las políticas estatales y las propias aspiraciones de los sectores populares.

\section{BIBLIOGRAFÍA}

ANDREOLI C., 2003, "Construcción con el sistema balloon-frame (viviendas de chapa y madera) en la localidad portuaria de Ingeniero White", Revista Registros, № 1, Mar del Plata, CEHAU-FAUD-UNMdP.

ARMUS, DIEGO Y HARDOY, JORGE ENRIQUE, 1990, "Conventillos, ranchos, y casa propia en el mundo urbano del novecientos", en Armus, Diego (comp.), Mundo Urbano y Cultura popular, Buenos Aires, Sudamericana.

BALLENT, ANAHÍ, 1990, "La Iglesia y la vivienda popular: la Gran Colecta Nacional de 1919", en Armus, Diego (comp.), Mundo Urbano y Cultura popular, Buenos Aires, Sudamericana. BRUNO, PERLA, 1997, "Supremacía de la seguridad y la higiene, 1885-1933", en Mazza, Carlos (edit.), La ciudad de papel, Mar del Plata, FAUD-UNMdP.

BRUNO, PERLA, 1999, “Estratificación, normativa y representación”, Revista I+A, № 4, Mar del Plata, Grupo Editorial Sur-FAUD-UNMdP.

CACOPARDO, FERNANDO, 1997, "Aspectos materiales de una Mar del Plata "apócrifa”. Conflictos, representaciones y prácticas en el proceso de formalización de las riberas entre 1890 y 1939", en Cacopardo, Fernando (edit.), Mar del Plata. Ciudad e historia, Madrid-Buenos Aires, Alianza.

CACOPARDO, FERNANDO, 2003, La Modernidad en una ciudad mutante. Vivienda, sociedad y territorio en laprimera mitad de siglo XX, Mar del Plata, CEHAU-FAUD.

CACOPARDO, FERNANDO, 2004, “Maderera (arquitectura)”, en Liernur, Jorge Francisco y Aliata, Fernando (comp.), Diccionariode Arquitecturaen la Argentina, Tomo 4, Buenos Aires, Clarín.

CASTRO, MARTÍN OMAR, 200l, "Entre la unidad y la diversidad: el barrio Puerto de Mar del Plata y las iniciativas sociales católicas entre las décadas de 1920 y 1940", en Cacopardo, Fernando (edit.), ¿Quéhacer con la extensión? Mar del Plata, Ciudady Territorio. Siglos XIX y XX, Madrid-Buenos Aires, Alianza. 


\section{CUADERNQuBasid}

PRODUCCIÓN Y TRANSFORMACIÓN DE LA VIVIENDA PORTUARIA MARPLATENSE EN LA PRIMERA MITAD

DEL SXX

COVA, ROBERTO, 1981, “Mar del Plata. Sobre casillas y carpinteros”, Revista DANA, № 1l, Chaco, Imprenta Región.

GAZANEO, JORGE Y SCARONE, MABEL, 1967, Revolución industrial yequipamiento urbano, Buenos Aires, IAA.

GUTIÉRREZ, RAMÓN Y NICOLINI, ALBERTO, 2000, "La ciudad y sus transformaciones", Nueva Historia de la Nación Argentina, Tomo 4, Buenos Aires, Planeta.

GORELIK, ADRIÁN, 1994, "Lo global y lo local: un debate sobre el reformismo", Cuaderno del Ciesal №2/3, Rosario.

IBÁÑEZ, JOSÉ, 1988, "El Puerto que conocí en la década del cuarenta”, Mar del Plata, Gráfica Armedenho.

IRIGOIN, MARÍA ALEJANDRA, 1991, "La población, los habitantes y la trama social urbana, 1880-1940", en AA VV, Mar del Plata, una historia urbana, Buenos Aires, Fundación Banco de Boston.

LIERNUR, JORGE FRANCISCO, 1984, "Buenos Aires: la estrategia de la casa autoconstruida", en Sectores populares y vida urbana, Buenos Aires, CLACSO.

LIERNUR, JORGE FRANCISCO, 1993, "La ciudad efímera", en Liernur, Jorge Francisco y Silvestri, Graciela, El umbral de la metrópolis, Buenos Aires, Sudamericana.

LIERNUR, JORGE FRANCISCO, 1999, "Casas y Jardines. La construcción del dispositivo doméstico moderno (1870-1930)", en Devoto, Fernando y Madero, Marta (comp.), Historia de la vida privada en la Argentina, Tomo 2, Buenos Aires, Ed. Taurus.

PANERAI, PHILLIPPE, DEMORGON, MARCELLE Y DEPAULE, JEAN CHARLES, 1983, Elementos de análisis urbano, Madrid, Instituto de Estudios de Administración Local.

RAMOS, JORGE, 1998, "La habitación popular urbana en Buenos Aires. 1880-1945. La mirada tipológica", Revista IAA, № 9l, Buenos Aires, Instituto de Arte Americano e Investigaciones Estéticas.

RIGOTTI, ANA MARÍA, 2000, "La ciudad y la vivienda como ámbitos de la política y la práctica profesional", Nueva Historia Argentina, Tomo 6, Buenos Aires, Sudamericana.

ROMERO, LUIS ALBERTO, 1995, "Los sectores populares urbanos como sujetos históricos", en Gutiérrez, Leandro y Romero Luis Alberto, Sectores populares, cultura y política. Buenos Aires en la entreguerra, Buenos Aires, Sudamericana.

SILVESTRI, GRACIELA Y PAIVA, VERÓNICA, 2004, "Higienismo", en Liernur, Jorge Francisco y Aliata, Fernando (comp.), Diccionario de Arquitectura en la Argentina, Tomo 3, Buenos Aires, Clarín. 


\section{Mariana Fernández Olivera}

PRODUCCIÓN Y TRANSFORMACIÓN DE LA VIVIENDA PORTUARIA MARPLATENSE EN LA PRIMERA MITAD DEL SXX

\section{OTRAS FUENTES}

Boletines Municipales

Expedientes Municipales de Obras Públicas

Expedientes Municipales de Obras Privadas

Folletos Inmobiliarios de varios martilleros

Plano de ocupación de 1924, plano catastral en base a la aerofoto de 1935 y plano catastral

de 1936

Planchetas catastrales

Reglamento General de Construcciones de 1937

Revistas Caras y Caretas de Buenos Aires

Semanario El Puerto de Mar del Plata. 
